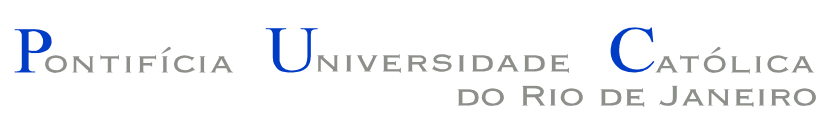

Suelen Maria Mariano de Sousa

\title{
A realização de um imaginário sobre a seca de 1915 a partir do romance de Rachel de Queiroz
}

Dissertação de Mestrado

Dissertação apresentada como requisito parcial para obtenção do grau de Mestre pelo Programa de Pós-Graduação em História Social da Cultura do Departamento de História do Centro de Ciências Sociais da PUC-Rio.

Orientador ${ }^{\mathrm{a}}$ : Prof ${ }^{\mathrm{a}}$ Flávia Maria Schlee Eyler 


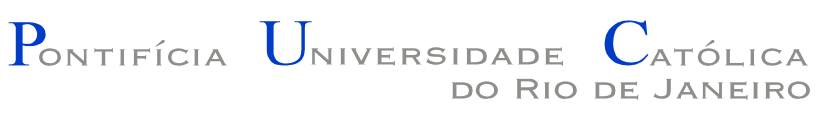

\section{Suelen Maria Mariano de Sousa}

\section{A realização de um imaginário sobre a seca de 1915 a partir do romance de Rachel de Queiroz}

Dissertação apresentada como requisito parcial para obtenção do grau de Mestre pelo Programa de Pós-Graduação em História Social da Cultura do Departamento de História do Centro de Ciências Sociais da PUC-Rio.

Aprovada pela Comissão Examinadora abaixo assinada.

Prof ${ }^{a}$ Flávia Maria Schlee Eyler

Orientadora

Departamento de História

PUC-Rio

\section{Prof ${ }^{\text {a }}$ Monica Pimenta Velloso \\ Setor de História \\ Fundação Casa de Rui Barbosa}

\section{Profa Márcia de Almeida Gonçalves \\ Departamento de História \\ PUC-Rio}

Profo Nizar Messari

Vice-Decano de Pós-Graduação do Centro de Ciências Sociais

PUC-Rio

Rio de Janeiro, 10 de agosto de 2009. 
Todos os direitos reservados. É proibida a reprodução total ou parcial do trabalho sem autorização da universidade, da autora e do orientador.

\section{Suelen Maria Mariano de Sousa}

Graduou-se em História na PUC-Rio em Janeiro de 2007. Foi bolsista de Iniciação Científica do projeto "História da Retórica na Grécia Antiga", sob orientação de Flavia Maria Schlee Eyler (PUC-Rio), assim como do projeto "A Cidade em Revistas: boemia literária e vida cultural no Rio de Janeiro (19001930)", sob orientação de Monica Pimenta Velloso (Fundação Casa de Rui Barbosa). Atualmente é doutoranda do Programa de Pós-Graduação em Letras da PUC-Rio.

Ficha Catalográfica

Sousa, Suelen Maria Mariano de

A realização de um imaginário sobre a seca de 1915 a partir do romance de Rachel de Queiroz / Suelen Maria Mariano de Sousa; orientadora: Flávia Maria Schlee Eyler. - 2009.

99 f.; $30 \mathrm{~cm}$

Dissertação (Mestrado em História)-Pontifícia Universidade Católica do Rio de Janeiro, Rio de Janeiro, 2009.

Inclui bibliografia

1. História - Teses. 2. História social da cultura. 3. Real. 4. Fictício. 5. Imaginário. 6. Alteridade. I. Eyler, Flávia Maria Schlee. II. Pontifícia Universidade Católica do Rio de Janeiro. Departamento de História. III. Título. 


\section{Agradecimentos}

Inicialmente, agradeço aos meus pais e irmãos que me incentivaram ao longo de toda minha trajetória e que compreendem o tamanho dessa conquista.

À minha querida orientadora Flávia Maria Schlee Eyler que tem me acompanhado nesse percurso de conhecimento com ensinamentos, apoio e afeto.

Agradeço aos professores do programa de pós-graduação dessa Universidade que engrandeceram o meu trabalho com suas aulas. Destaco aqui o professor Ricardo Benzaquen de Araújo, que, com toda sua erudição, me possibilitou correlacionar elementos aparentemente díspares na composição dessa dissertação.

À Márcia Gonçalves e Monica Pimenta Velloso, agradeço por aceitarem participar dessa defesa. Suas considerações foram muito bem acolhidas e contribuiram para o enriquecimento desse trabalho.

Aos amigos que me acompanharam todo o tempo e compartilharam as angústias e alegrias advindas desses anos de pesquisa. Com amor imenso dedico esse trabalho a eles que, assim como meus familiares, sabem o valor dessa realização. Agradeço à Kátia, à Roberta e à pequena Renata Ava, às três Antunes, que sempre me incentivaram e me fortaleceram com suas amizades. Ao meu querido Ricardo Jacob, amigo-irmão, que sempre acreditou na minha capacidade. À Marina da Silva, que mesmo à distância alegrou meus dias. À Beth Godoy, amiga de todas as horas, companheira de estudos, dificuldades e vitórias. À Graça Salgado, que foi mais que professora, foi incentivadora e amiga. Ao Fábio Bertacini, agradeço o amor e o incentivo que tem me dedicado. Ao doutor César Conde que me ajudou a recuperar a vontade, a retomar o caminho que escolhi, e a manter a "sanidade". E, por fim, mas com igual atenção, agradeço enormemente ao Gustavo Broetto que idealizou, acompanhou e motivou a elaboração desse Mestrado.

Ao auxílio oferecido pela CAPES ao longo desses anos, muito obrigada. 
A vida, prezado leitor, é uma sucessão de acontecimentos monótonos, repetidos e sem imprevisto. Por isto alguns homens de imaginação foram obrigados a inventar o romance. O homem, na Terra, nasce, vive e morre sem que lhe aconteça nenhuma dessas aventuras pitorescas de que os livros estão cheios. (VERÍSSIMO, 1976, p. 298) 


\section{Resumo}

Sousa, Suelen Maria Mariano de; Eyler, Flávia Maria Schlee. A Realização de um Imaginário sobre a Seca de 1915 a partir do Romance de Rachel de Queiroz. Rio de Janeiro, 2009, 99 p. Dissertação de Mestrado - Departamento de História, Pontifícia Universidade Católica do Rio de Janeiro.

A narrativa literária abre a possibilidade tanto para o leitor, quanto para o autor, de vivência de outras experiências, inimagináveis no cotidiano de ambos. A imaginação entra em cena, e concede inúmeras possibilidades de significações delimitando a especificidade do discurso ficcional literário, que se destaca de outras formas discursivas por nele se estabelecer a tematização do imaginário. A formação discursiva da obra literária é própria à literatura. Como "discurso do imaginário", devolve para o sujeito a diferença e não apenas o esperado. A partir dessa premissa utilizo o romance de Rachel de Queiroz, O Quinze, como objeto de análise. A autora "irrealiza" a seca de 1915 de maneira que ao seu leitor é dada a possibilidade de ativação de um imaginário em que uma calamidade física atua no indivíduo de tal forma que é capaz de lhe moldar ou de acentuar a firmeza de seu caráter. Busca-se enfatizar a existência de um outro caminho para a realização do trabalho historiográfico que tem como objeto obras ficcionais. Ressalta-se o caráter não documental da literatura e o trabalho com a ficção a partir de sua funcionalidade. Desse modo, não creio que se encontre identidades prontas em uma obra literária. As personagens de um texto ficcional estão em permanente processo de construção. São inacabadas, prontas a ser e a vir-a-ser sempre que reclamadas no ato da leitura. A autora não forja uma identidade de nordestino. Ela abre um campo onde não se encontra $o$ nordestino, mas sim um sujeito que passa por adversidades e que pode se tornar outro e vários. A realidade extratextual da seca é irrealizada no romance, tornando possível a realização de um imaginário sobre a seca e sobre esse sujeito nordestino. Assim, no texto, experimentamos alteridades.

\section{Palavras-chaves}

Real; Fictício; Imaginário; Alteridade. 


\section{Abstract}

Sousa, Suelen Maria Mariano de; Eyler, Flávia Maria Schlee (Advisor); The accomplishment of an imaginary one on the drought of 1915 starting from the romance of Rachel de Queiroz. Rio de Janeiro, 2009, 99 p. MSc. Dissertation - Departamento de História, Pontifícia Universidade Católica do Rio de Janeiro.

The literary narrative certainly opens unimaginable possibilities for both, reader and author, in their daily routines. The imagination enters the scene here and conceives numerous possibilities of meanings, therefore restraining the specificity of the fictional literary speech, which stands out for conceiving in its form the imaginary theme. The formulation of the literary work is then concerned to literature. As an "imaginary speech" it gives back the difference to the individual (subject), and not just simple expectations. From this concept, the present study takes Rachel de Queiroz's novel, O Quinze, as an object of analysis. The author does not "realize" the drought of 1915, therefore allowing the reader to bring the imaginary into action in which the physical endurance and suffering act on the individual, building up, or even affirming, his character. Our research emphasizes on the existence of an alternate path for working the historiography from the fictional books. In one hand, this study focuses the non-document character of literature, an in other the possibility of working with a fictional book from its functionality. From this perspective we do not intend to find full identities in a literary work. The characters of a fictional work are constantly in build up process. They are, therefore, unfinished, ready to be and to become recalled in the act of reading. Rachel de Queiroz doesn't create an identity for the typical inland man called "nordestino", but an individual who, going through rough situations, could become another and various others. The drought reality beyond the written text is not realized in the novel, but makes possible the realization of an imaginary of the drought and of its inland individual, the nordestino. This way, in the text, we experience alterity.

\section{KeyWords}

Real; Fictitious; Imaginary; Alterity. 


\section{Sumário}

$\begin{array}{ll}\text { Introdução } & 09\end{array}$

1. O veto ao ficcional e a opção por uma literatura documental 19

2. O controle do imaginário na tentativa de criação de uma literatura nacional

3. A "irrealização" da seca de 1915

4. Considerações Finais

5. Referências Bibliográficas

5.1 Fontes Primárias

5.2. Fontes Secundárias 